protect the person with a mental handicap from harm and to prosecute the offenders when appropriate. The current difficulties with using Section 7 (Guardianship) of the 1983 Mental Health Act have arisen because of the wording of that Section, which includes in mental disorder mental impairment, but not mental handicap. The definition of mental impairment is given as "a state of arrested or incomplete development of mind which includes significant impairment of intelligence and social functioning and is associated with abnormally aggressive or seriously irresponsible conduct". The majority of people with a mental handicap do not display abnormally aggressive conduct and are therefore excluded from the Act on those criteria. The term "seriously irresponsible" is not defined and has given rise to a lot of debate on what constitutes seriously irresponsible conduct. Most psychiatrists would consider it to mean behaviour that is antisocial in some way and causing harm to other people, but it could be considered to describe the difficulties of mentally handicapped people in guarding themselves against danger or exploitation. In the latter case, then, Section 7 could be used for those people who need protection. This point needs to be clarified. Both Scotland and Northern Ireland have retained the term "mental handicap" in their legislation, which has enabled them to continue using guardianship. Other sections of the 1983 Mental Health Act which can be used by approved social workers when abuse is suspected are Section 115 and Section 135. However, these have both proved unsatisfactory due to their strict criteria and limitations. The difficulty in obtaining individual prosecutions was mentioned by several respondents to the survey. If the person on whom the offence was committed is unable to give evidence due to poor verbal or communicative skills, then the case may not even be brought to court if there is no corroborating evidence. It is therefore important to obtain as much scientific and photographic evidence as possible. It may be easier to prove sexual abuse in the future with the use of DNA 'fingerprinting' of semen or body fluids.

An amendment to the 1983 Mental Health Act to enable guardianship to be used once more for the protection of adults with a mental handicap would, in my opinion, be a major advance in tackling this problem. Whether this occurs or not, it is essential that all professionals working in this field are aware of the problem and that districts have locally agreed strategies for dealing with abuse when it occurs.

\section{Acknowledgements}

I would like to thank all my colleagues who participated in the survey and Dr J. Jancar for his help and advice.

\section{References}

COOKE, L. B. (1989) Abuse of mentally handicapped adults. British Medical Journal, 229, 392.

JANCAR, J. \& JohnSTON, S. J. (1990) Incest and mental handicap. Journal of Mental Deficiency Research (in press).

\title{
Suicide and life insurance
}

\section{T. J. O'Grady, Consultant Psychiatrist; R. NAIK, SHO; E. ButTerworth, Sister, Deliberate Self Harm Team, The Peter Hodgkinson Centre, County Hospital, Lincoln LN2 5QY}

In the study of suicide little attention has been paid to the role of life insurance. One might suppose that 'deliberately accelerating the event insured against' by homicide or suicide would void a policy. One might also predict that changes in attitude towards suicide, so that it is increasingly regarded as a medico-social problem rather than a criminal act, would be reflected in a softening of attitude among insurers. On the other hand, recent epidemiological changes, such as the increased suicide rate among young males, could make companies reluctant to relax their policy conditions. 
Over a century ago, Westcott (1885) carried out a survey of insurance companies and discovered that of 32 companies, nine made no mention of suicide in their prospectus and six companies' policies were voided by suicide. The remainder revealed policies not void if they had been in force for between one and five years. We report on a similar survey designed to update our knowledge of current insurance practice.

\section{The study}

On behalf of the Lincoln Deliberate Self Harm Team, we obtained the names of 42 insurance companies from the Lincolnshire Yellow Pages. Our selection included all the major national insurance companies together with some minor local ones. We wrote to the companies asking if they could clarify their policy regarding the payment of insurance benefits to the bereaved families of suicide victims. In particular, we asked whether the full benefit was payable at death or if a percentage of the total sum was withheld if the cause was suicide. We also asked whether the coroner's verdict affected the decision on payment or whether other criteria were used to define suicide.

\section{Findings}

We received replies from 28 of the 42 companies. The 20 major national companies replied but some smaller local companies did not. Ten of the companies said that they would pay out regardless of the time interval from the onset of the policy. Nine said that they would pay out after the policy had been in force for 12 months. Six would pay out after 13 months and one after 24 months. Two companies reserve the right to refuse payment of all benefits.

All the companies stressed that they would reserve the right of refusal of payment if there had been nondisclosure of relevant medical information, e.g. a history of mental illness or previous suicidal attempts. In the case of endowment policies designed to repay mortgages, there are generally no restrictions on payment.

Of the 16 companies who would pay out benefit after a period of time from the onset of the policy, seven of them said that they would return the premiums if the suicide occurred before their set time limit and the other nine said that they would pay out no money whatsoever if suicide had occurred.

One of the companies stated that the "coroner's verdict is not of much interest as the standard of proof required for a suicide verdict is different from that required for a civil law case which might result from a rejected claim". All the other companies said that they would accept the coroner's verdict but would not necessarily regard it as being conclusive.

Companies did not disclose what criteria they used to define suicide nor their methods of investigating deaths of questionable cause.

\section{Comment}

Companies remain sympathetic to claims in the event of suicide and there has been surprisingly little change in attitude since 1885. Modern attitudes towards suicide were formed during the 19 th century (Mohanna, 1989) and by 1885 , most suicides were felt to result from 'unsound mind' rather than criminality. This impression is consistent with most recent case studies (e.g. Barraclough, 1974), and has seldom been challenged. Westcott (1885) noted that only one of 32 companies bothered to distinguish between "suicide of the insane and felo-de-se". Eight of these 32 companies are still in existence in similar form. None had significantly changed their policies except to reduce the time limit for payment to one year.

It is not clear why smaller companies tended not to reply. Larger companies probably have more efficient customer relations departments. We have no evidence that smaller companies take a different attitude to suicide, but this remains a possible source of bias.

Interestingly, few references to life insurance are made in case studies of suicides in modern literature. It is possible, however, that life insurance should be considered as a factor in suicidal behaviour and that this possibility should stimulate further study.

A further point is that insurance companies possess an important fund of data on suicide. The methodology they use in investigating cases would be of interest to clinicians and coroners. Cases where life insurance was suspected as being a precipitating factor in suicide would particularly merit research.

\section{References}

BArRaclough, B. M., Bunch, J., Nelson, B. \& SAInsBury, P. (1974) A hundred cases of suicide. British Journal of Psychiatry, 125, 355-373.

MohanNA, M. (1989) The medicalisation of suicide in 19th century Britain. Abstracts: Autumn Meeting of Royal College of Psychiatrists 1989.

WestCoTt, W. W. (1885) Suicide. London: H.K. Lewis. 